\title{
Outdoor air pollution and respiratory health: a bibliometric analysis of publications in peer-reviewed journals (1900 - 2017)
}

Waleed M. Sweileh', Samah W. Al-Jabi², Sa'ed H. Zyoud² and Ansam F. Sawalha ${ }^{* *}$

\begin{abstract}
Background: Outdoor air pollution is a major threat to global public health that needs responsible participation of researchers at all levels. Assessing research output is an important step in highlighting national and international contribution and collaboration in a certain field. Therefore, the aim of this study was to analyze globally-published literature in outdoor air pollution - related respiratory health.

Method: Outdoor air pollution documents related to respiratory health were retrieved from Scopus database. The study period was up to 2017. Mapping of author keywords was carried out using VOSviewer 1.6.6.

Results: Search query yielded 3635 documents with an $h$-index of 137. There was a dramatic increase in the number of publications in the last decade of the study period. The most frequently encountered author keywords were: air pollution (835 occurrences), asthma (502 occurrences), particulate matter (198 occurrences), and children (203 occurrences). The United States of America ranked first (1082; 29.8\%) followed by the United Kingdom (279; 7. 7\%) and Italy (198; 5.4\%). Annual research productivity stratified by income and population size indicated that China ranked first (22.2) followed by the USA (18.8). Analysis of regional distribution of publications indicated that the Mediterranean, African, and South-East Asia regions had the least contribution. Harvard University $(92 ; 2.5 \%)$ was the most active institution/organization followed the US Environmental Protection Agency (89; 2.4\%). International collaboration was restricted to three regions: Northern America, Europe, and Asia. The top ten preferred journals were in the field of environmental health and respiratory health. Environmental Health Perspective was the most preferred journal for publishing documents in outdoor pollution in relation to respiratory health.

Conclusion: Research on the impact of outdoor air pollution on respiratory health had accelerated lately and is receiving a lot of interest. Global research networks that include countries with high level of pollution and limited resources are highly needed to create public opinion in favor of minimizing outdoor air pollution and investing in green technologies.
\end{abstract}

Keywords: Outdoor air pollution, Respiratory health, Bibliometric analysis

\footnotetext{
* Correspondence: ansam@najah.edu; ansam1969@yahoo.com

'Division of Biomedical Sciences, Department of Physiology, Pharmacology and Toxicology, College of Medicine and Health Sciences, An-Najah National University, Nablus, Palestine

Full list of author information is available at the end of the article
}

(c) The Author(s). 2018 Open Access This article is distributed under the terms of the Creative Commons Attribution 4.0 International License (http://creativecommons.org/licenses/by/4.0/), which permits unrestricted use, distribution, and reproduction in any medium, provided you give appropriate credit to the original author(s) and the source, provide a link to the Creative Commons license, and indicate if changes were made. The Creative Commons Public Domain Dedication waiver (http://creativecommons.org/publicdomain/zero/1.0/) applies to the data made available in this article, unless otherwise stated. 


\section{Background}

Outdoor air pollution is defined as the presence of one or more substances in the atmospheric air at concentrations and duration above the natural limits [1]. Such substances include ozone [O3], airborne lead [Pb], carbon monoxide [CO], sulphur oxides [SOx] and nitrogen oxides [NOx] [2]. Recently, air pollution with particulate matters (PM), especially those with less than $2.5 \mu \mathrm{m}$, has been the focus of most outdoor air pollution studies due to its ability to penetrate the lung tissue and induce local and systemic effects [2].

Air pollution has been described as one of the "great killers of our age" and as "major threat to health" due to its tremendous and various health effects on humans of all ages and in both genders [3, 4]. In 2014, the World Health Organization (WHO) estimated that $92 \%$ of the world population was living in places with less than optimum outdoor air quality. Furthermore, WHO reported that in 2012, outdoor air pollution caused around 3 million deaths worldwide and 6.5 million deaths (11. $6 \%$ of all global deaths) were associated with indoor and outdoor air pollution together [5].

Air pollution was linked to cancer, respiratory diseases, negative pregnancy outcomes, infertility, cardiovascular diseases, stroke, cognitive decline, and other adverse medical conditions [6-13]. Nearly 90\% of air-pollution-related deaths occur in low- and middle-income countries, with nearly 2 out of 3 occurring in South-East Asia and Western Pacific regions. The problem of outdoor pollution is not a new one, but the rapid urbanization, particularly in Asia, made the problem of air pollution more visible and its health burden more tangible [14-17].

Bibliometric analysis is the application of statistical methods on published literature to analyze publication trends with time and to shed light on influential researchers, countries, and institutions in the field. In the past decade, at least seven bibliometric studies on air pollution were published [18-24]. However, none of the published bibliometric studies have shed light on the air pollution - related respiratory health. Therefore, in the current study, we aim to analyze literature pertaining to outdoor air pollution and respiratory health. The size of the literature and research productivity in this field is a good indicator of national and international efforts to improve air quality and to decrease the health and economic burden of air pollution. Furthermore, the quality of the air we breathe is the responsibility of everyone including researchers and academics. This study comes in line with perceived personal responsibility toward better air quality.

\section{Method}

\section{Search strategy}

This study aimed to analyze the documents about outdoor air pollution - related respiratory health. Scopus database was used to retrieve relevant documents because of its advantages over other databases [25-28]. The search strategy developed for this study consisted of nine steps (Additional file 1). The first six steps utilized various keywords and search queries to retrieve the maximum number of documents. Keywords included in search queries were those found in recent relevant systematic reviews [6, $12,13,29,30]$. The combined result of search queries underwent a filtration process by adding exclusion and limitation components (steps $7-9$ ).

False positive results were minimized by using title search. Therefore, all retrieved documents have the keywords of interest. Despite that, false positive results need to be searched by reviewing the retrieved documents. The review process was carried out on a sample of 200 documents chosen based on the number of citation. The review process was carried out by the authors (W.S and A.J) and approved by a third author (A.S). Keywords of the irrelevant documents (false positive results) were used in the exclusion step. A complete list of irrelevant keywords is written in Additional file 1. The exclusion of false positive results is not enough to confirm the validity of the search strategy. Therefore, the authors compared two different methods of data collection. In the first one, we collected data regarding research output for each of the most active authors as obtained through the search strategy, whilst in the second one, the research output of each of the most active authors was extracted and reviewed by exploring the author profile as presented by Scopus. The extent of agreement between the two methods is measured by interclass correlation coefficient using SPSS [31-35]. An excellent agreement between the two methods with an interclass correlation above $95 \%$ and a $p$ less than $5 \%$ is indicative of high validity of the search strategy. In the current study, the interclass correlation was $0.98 .7 \%$ and $p$ was 0.001 .

The retrieved data were also sorted based on the number of different country affiliations per article to calculate international collaboration. Documents with authors from different countries represent international or inter-country collaboration while documents in which all authors have one country affiliation represent intra-country collaboration. It should be emphasized that Scopus has the function which can separate documents with intra or inter - country collaboration. Therefore, the calculation of international collaboration was extracted from data provided by Scopus.

\section{Bibliometric analysis versus systematic reviews}

It should be emphasized that the bibliometric analysis is not the same as systematic reviews. In contrast to systematic reviews, bibliometric analysis focuses on quantitative and qualitative aspects of all documents retrieved from one electronic large database. In bibliometric analysis, the investigated research question is the volume of research published, how this volume of literature evolved with time, 
what major topics were of high interest, and the scientific impact of literature in a particular subject. However, in systematic reviews, a complete and exhaustive summary of current literature obtained from several electronic databases and relevant to a research question is provided.

In bibliometric analysis, only one large and well known database, such as Scopus, is used. Therefore, the retrieved documents will not include any duplicates. On the other hand, duplicate documents might appear in systematic reviews because several databases are used to retrieve the required documents.

\section{Data analysis and visualization}

In this study, Hirsch-index ( $h$-index) was used as a measure of impact of publications [36]. Graphs were created using Statistical Package for Social Sciences (SPSS). Hirsch - index is defined as the number of articles (n) that have received at least $\mathrm{n}$ citations [36]. VOSviewer software was used to create visualization maps while ArcMap 10.1 was used to create geographical distribution of the retrieved documents [37-39]. For VOSviewer mapping of most frequent author keywords, a minimum occurrence of 10 was used as a cut-off point for inclusion of the keyword in mapping analysis. Analysis also included distribution of publications based on World Health Organization (WHO) regions.

\section{Results}

\section{Types and growth of publications}

The search strategy yielded 3635 documents. The earliest document in this field was published in 1943 in American Journal of Epidemiology [40]. The analysis of the types of documents showed that research articles (2935, 80.7\%) were the most common type followed by review articles (359; 9.9\%). The remaining documents (341; 9.4\%) were conference papers, letters, editorials, short surveys, and notes. English $(2923,80.4 \%)$ was the primary language of documents followed by French (156; 4.3\%) and German (124; 3.4\%). The subject areas of the documents were medicine $(2772 ; 76.3 \%)$ followed by environmental science (1038; 28.6\%) and biochemistry/ genetics/ molecular biology $(317 ; 8.7 \%)$ with the possibility of overlap among different subject areas. The growth of publications showed a dramatic increase in the past decade. Figure 1 shows the annual growth of publications. There was a $72 \%$ increase in number of publications in 2017 compared to that in 2008.

\section{Author keywords}

Analysis of author keywords showed that the most frequently encountered author keywords were: air pollution (835 occurrences), asthma (502 occurrences), particulate matter (198 occurrences), and children (203 occurrences) (Fig. 2a). Further mapping of types of pollutants most commonly encountered in author keywords showed that particulate matter (198 occurrences), ozone (192 occurrences), nitrogen oxide (95 occurrences), PM10 (75 occurrences), PM2.5 (57 occurrences), and Sulfur dioxide (54 occurrences), were the most frequently encountered author keywords (Fig. 2b).

\section{Active journals}

Table 1 shows the top ten journals that were involved in publishing the retrieved documents. Environmental Health Perspective was the most active journal $(153 ; 4$. 2\%) followed by Environmental Research (112; 3.1\%) and American Journal of Respiratory and Critical Care Medicine $(100 ; 2.8 \%)$. The top ten active journals included four in the field of environmental health, four in the field of respiratory health, one in allergy/immunology, and the last one in toxicology field.

\section{Authorship analysis}

The number of different author names who participated in publishing documents was 11,014; giving an average of 3.0 authors per document. Table 2 lists the top ten active authors with their affiliations. The top active authors were mainly from Western and Northern Europe, particularly from the Netherlands, Italy, and the United Kingdom [21]. Prof. Brunekreef, B. from the Netherlands was the most active researcher in this field with 77 (2.2\%) documents. Authors with a minimum productivity of 20 publications were also visualized using network visualization map that showed research networking among active authors (Fig. $3)$. The map showed that active authors with minimum productivity of 20 publications existed in four clusters. The largest cluster consisted of eight authors (dark red color). The second cluster consisted of seven authors (green). The third cluster consisted of six authors (blue). The fourth cluster consisted of four researchers (dark yellow). Authors with minimum productivity of 20 publications who are not shown in the map are usually those who did not exist within a research network that has prominent productivity.

\section{Active countries}

Researchers from 92 different countries contributed to the retrieved documents. Table 3 lists the top ten countries actively involved in air pollution - related respiratory health. Researchers from the USA participated in publishing 1082 (29.8\%) documents. The top 10 list included countries from Northern America, Western Europe, and Asia. Researchers from these top ten countries participated in publishing 2630 (72.3\%) documents. Figure 4 shows worldwide geographical distribution of retrieved documents. Regional distribution of retrieved documents indicated that the regions of Americas, Europe, and Western pacific had the highest percentage 


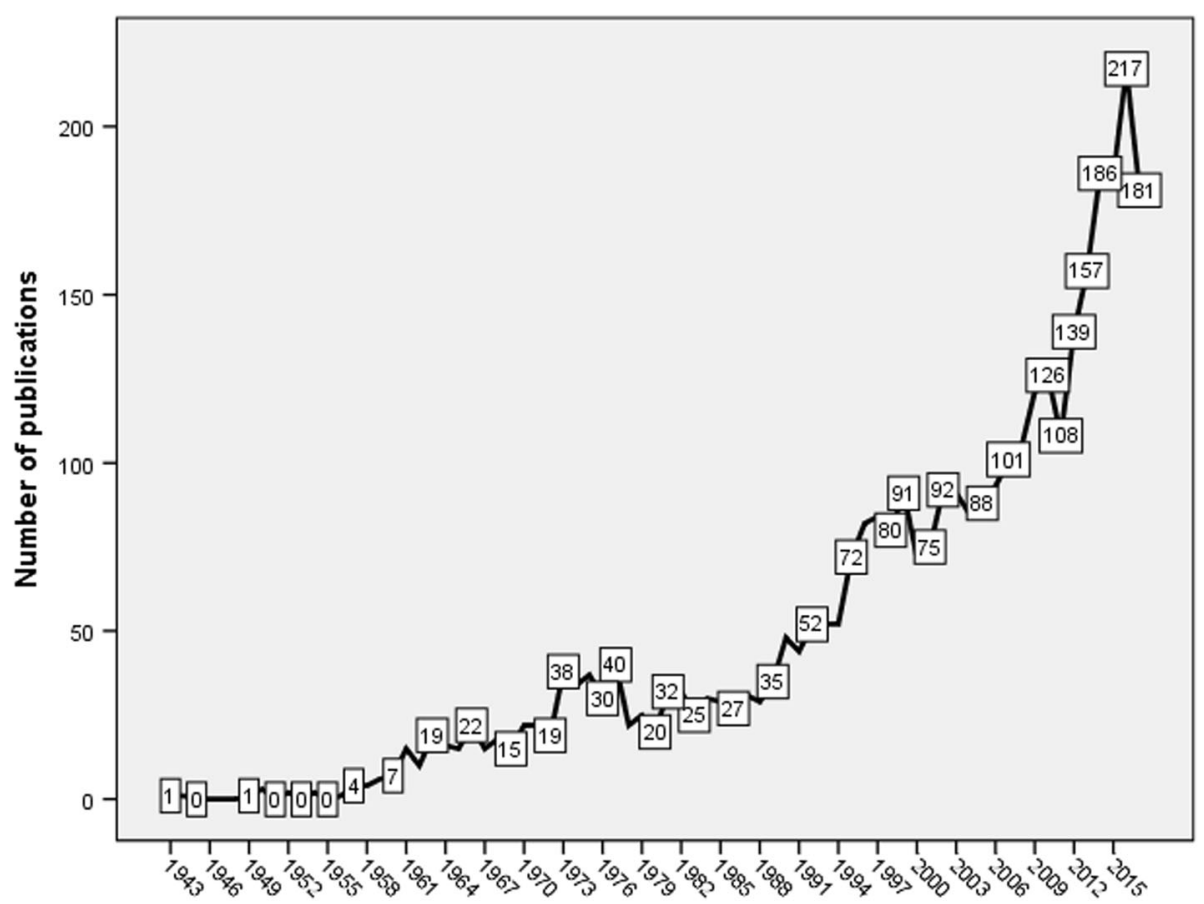

Fig. 1 Annual growth of publications in Outdoor air pollution and respiratory health (1900 - 2017)

of contribution while Mediterranean, Africa, and SouthEast Asia regions had the least contribution (Fig. 5).

\section{International collaboration}

International collaboration in air pollution - related respiratory health showed that there were three clusters. There was relatively adequate collaboration among countries within each cluster and there was adequate collaboration between countries in the two different clusters (Fig. 6). The first cluster consisted of 9 European countries shown in green color while the second cluster consisted of 9 countries in different regions in the world particularly those in Northern and Southern America, South East Asia, and Western Pacific regions. The third cluster consisted of one item, India with research connections with countries in both cluster number 1 and 2 . International collaboration among countries in the Mediterranean region, Africa, or Eastern Europe and those in Northern America, Europe, or Asia did not show up in the map.

Table 3 shows the extent and the percentage of intra and inter (international) country collaboration for the top active countries. In terms of quantity, the USA had the largest number of documents $(276 ; 25$. $5 \%$ with international authors. However, this quantity represents only $25.5 \%$ of total research productivity from the USA which means that approximately $75 \%$ of USA research production in this field was produced by authors from the USA without collaboration with international researchers. Japan had the least percentage $(22.2 \%)$ of international collaboration while Sweden had the largest percentage $(58.0 \%)$ of documents with international collaboration.

\section{Active institutions}

Harvard University ranked first in research output (92; $2.5 \%)$ and in the impact of publications ( $h$-index =44). The US Environmental Protection Agency (EPA) ranked second in research output $(89 ; 2.4 \%)$ and in the impact of publications ( $h$-index $=36$ ). Table 4 shows the top ten active institutions/organizations. The list included seven academic institutions and three research centers. Six of the top active institutions were American institutions, three were European, and one was Canadian.

\section{Citation analysis}

The total number of citations received by documents was 101,113 , with an average of 27.8 citations per document. Range of citations was [ $0-4294]$. The $h$-index of the retrieved documents was 137 . Table 5 shows the top ten highly cited articles. The article that received the highest number of citations (4294) was published in 2002 in Journal of American Medical Association (JAMA) and discussed the relation between lung cancer, cardiopulmonary mortality and air pollution [40]. 


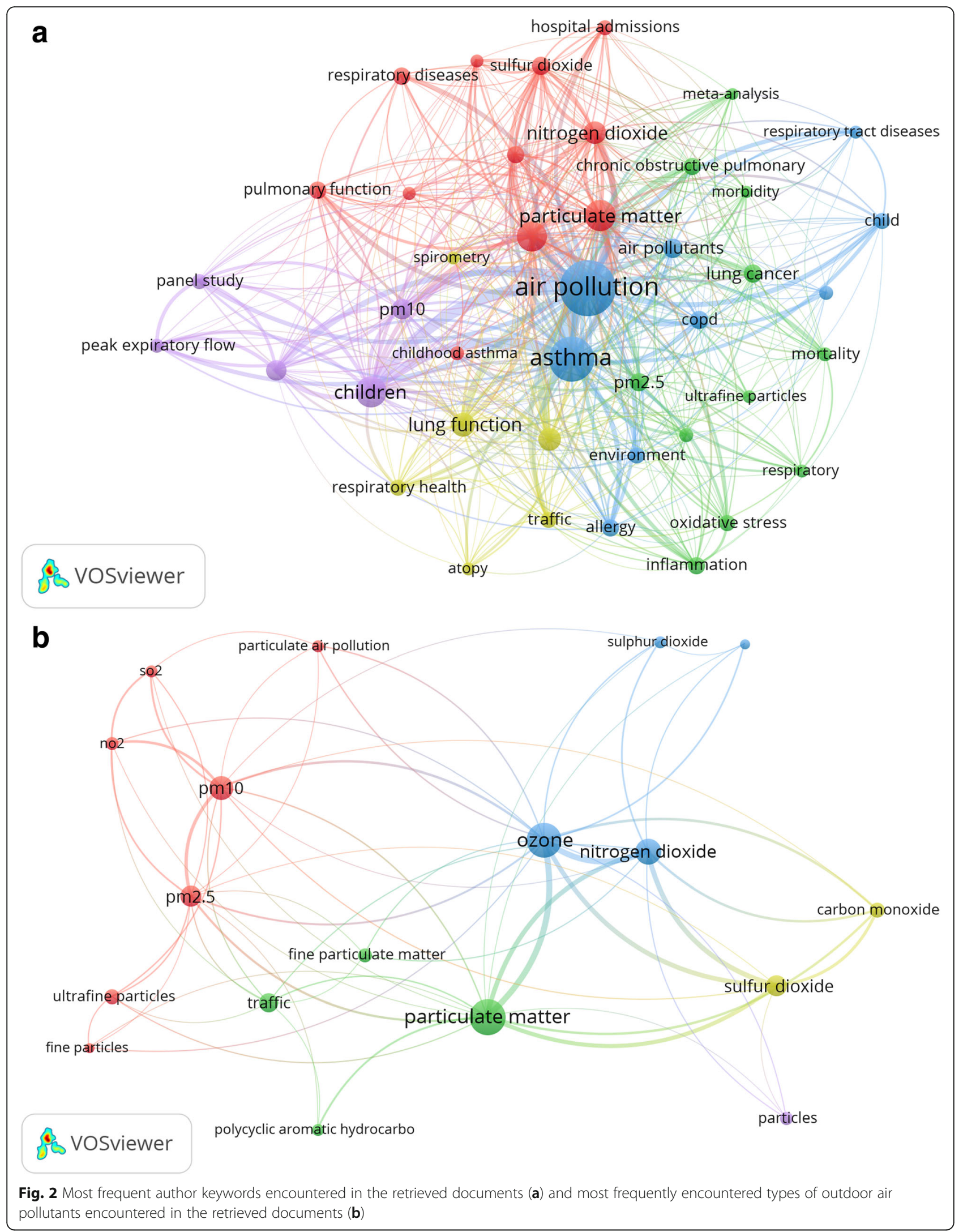


Table 1 Top active journals in publishing documents in air pollution - related respiratory health (1900 - 2017)

\begin{tabular}{lll}
\hline Journal & Frequency & $\%$ \\
\hline Environmental Health Perspectives & 153 & N=3635 \\
Environmental Research & 112 & 3.1 \\
American Journal Of Respiratory & 100 & 2.8 \\
And Critical Care Medicine & & \\
European Respiratory Journal & 90 & 2.5 \\
Archives Of Environmental Health & 89 & 2.4 \\
$\begin{array}{l}\text { Thorax } \\
\text { Journal Of Allergy And Clinical }\end{array}$ & 58 & 1.6 \\
Immunology & 54 & 1.5 \\
$\begin{array}{l}\text { American Review Of Respiratory } \\
\text { Disease }\end{array}$ & 52 & 1.4 \\
Inhalation Toxicology & & 1.4 \\
International Journal Of \\
$\begin{array}{l}\text { Environmental Research And } \\
\text { Public Health }\end{array}$
\end{tabular}

\section{Discussion}

\section{Growth of publications}

In this study, we analyzed global research output in outdoor air pollution - related respiratory health. The results showed a noticeable increase in the number of publications in the last decade of the study period. This indicates that the level of air pollution and its health consequences reached serious levels. In 2012, air pollution was responsible for 3 million deaths, representing 5 . $4 \%$ of the total global deaths. In the same year, about $25 \%$ were due to lung cancer deaths, $8 \%$ were due to chronic obstructive pulmonary disease (COPD) deaths, and about $17 \%$ of respiratory infection deaths were caused by outdoor air pollution [41]. A study indicated that the contribution of outdoor air pollution to global premature mortality could double by 2050 [42]. Another study concluded that outdoor air pollution contributes to the increase in global burden of COPD and that an increase of $10 \mu \mathrm{g} / \mathrm{m}^{(3)}$ in PM10 produced significant increase in COPD deaths and exacerbations that can be substantially reduced by controlling air pollution [43]. A cohort Chinese study concluded that the risks of mortality and years of life lost were elevated corresponding to an increase in current ambient concentrations of the air pollutants [44].

The contribution of researchers from /ifferent scientific fields led to an acceleration in the growth of publications in this field. Scientists in the fields of the environment, respiratory health, public health, and even molecular biology/genetics contributed to the retrieved documents [45-49]. The fact that air pollution is a multidisciplinary field created a large number of readers from different scientific fields and thus leading to large number of citations, reflected in the relatively high $h$-index value of documents. For example, the $h$-index of literature in global carbapenem resistance was 102 and that for literature in resistant tuberculosis was $76[50,51]$.

\section{Active countries and institutions}

Our results showed that China had the highest research productivity in terms of GDP per capita per year. In China, air pollution was previously estimated to contribute to 1.2 to 2 million deaths annually [52]. In its list of the world's deadliest countries for air pollution, the WHO ranked China first followed by India, Russian Federation, Indonesia, Pakistan, Ukraine, Nigeria, Egypt, USA, and Bangladesh [53]. Out of the top 10 countries that have high total annual number of deaths from PM2. 5 and PM10, only China and USA were among the top ten active countries in research output. The deadliest effects of air pollution in China led to the adoption of the Ambient Air Quality Standard in China in 2012 [54]. This system started a national Air Reporting System that now includes 945 sites in 190 cities.

Table 2 Most active researchers in the field of air pollution - related respiratory health (1900 - 2017)

\begin{tabular}{lllll}
\hline Rank & Researcher & Frequency & $\%$ & Affiliation \\
& & & N=3635 & \\
\hline 1st & Brunekreef, B. & 77 & 2.2 & Utrecht University, Utrecht, Netherlands \\
2nd & Hoek, G. & 62 & 1.7 & Utrecht University, Institute for Risk Assessment Sciences (IRAS), Utrecht, Netherlands \\
3rd & Schwartz, J. & 42 & 1.2 & Harvard School of Public Health, Department of Environmental Health, Boston, United States \\
4th & Künzli, N. & 38 & 1.0 & Swiss Tropical and Public Health Institute (Swiss TPH), Basel, Switzerland \\
5th & Heinrich, J. & 36 & 1.0 & Ludwig-Maximilians-Universitat Munchen, Social and Environmental Medicine, Munich, Germany \\
6th & Sunyer, J. & 33 & 0.9 & Instituto de Salud Global de Barcelona, Barcelona, Spain \\
7th & Linn, W.S. & 33 & 0.9 & University of Southern California, Department of Preventive Medicine, Los Angeles, United States \\
8th & Forastiere, F. & 29 & 0.8 & Lazio Regional Health Service, Department of Epidemiology, Roma, Italy \\
9th & Koenig, J.Q. & 28 & 0.8 & No affiliation available in Scopus \\
10th & Kelly, F.J. & 28 & 0.8 & King's College London, Faculty of Life Sciences and Medicine, London, United Kingdom \\
\hline
\end{tabular}




\section{Forsberg B. Kelly F.J. Hoek G. \\ Koenig J.Q. \\ katsouyannik. Brunekreef B. \\ Sunyer J. \\ Kramer U. \\ Schindler C. \\ Anderson H.R. \\ Pershagen G.}

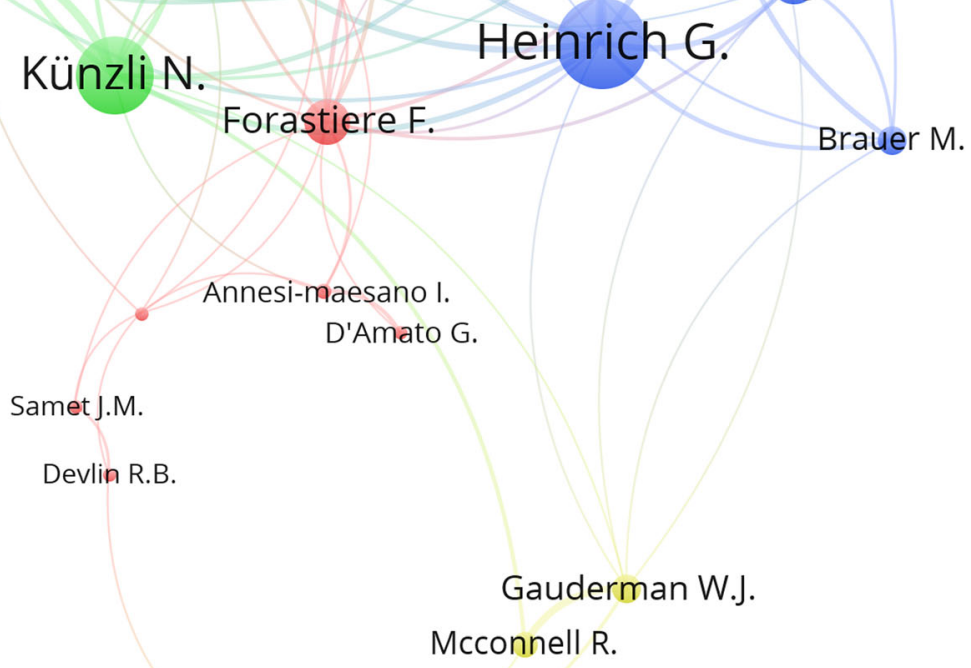

Linn W.S.

Hackney J.D.

Fig. 3 Network visualization map of authors with minimum productivity of 20 publications in the studied field and exist within a collaborative research group

Table 3 Top 10 active countries in publishing documents in air pollution - related respiratory health (1900 - 2017)

\begin{tabular}{|c|c|c|c|c|c|}
\hline Country & $\begin{array}{l}\text { Frequency (\%) } \\
N=3635\end{array}$ & $\begin{array}{l}\text { GDP per capita } \\
\left({ }^{\mathrm{a}} 10^{3}\right) \text { USD per year }\end{array}$ & $\begin{array}{l}\text { Productivity } \\
\text { per GDP/ } \\
\text { capita/year }\end{array}$ & $\begin{array}{l}\text { Intra-country } \\
\text { collaboration }\end{array}$ & $\begin{array}{l}\text { Inter - } \\
\text { country } \\
\text { collaboration }\end{array}$ \\
\hline United States & $1082(29.8)$ & 57.467 & 18.8 & $806(74.5)$ & $276(25.5)$ \\
\hline United Kingdom & $279(7.7)$ & 39.899 & 7.0 & $152(54.5)$ & $127(45.5)$ \\
\hline Italy & $198(5.4)$ & 30.527 & 6.5 & $131(66.2)$ & $67(33.8)$ \\
\hline France & $196(5.4)$ & 36.855 & 5.3 & $130(66.3)$ & 66 (33.7) \\
\hline China & $180(5.0)$ & 8.123 & 22.2 & $90(50.0)$ & $90(50.0)$ \\
\hline Canada & $169(4.6)$ & 42.158 & 4.0 & $93(55.0)$ & $76(45.0)$ \\
\hline Germany & $169(4.6)$ & 41.936 & 4.0 & 101 (59.8) & $68(40.2)$ \\
\hline Netherlands & 121 (3.3) & 45.295 & 2.7 & $55(45.5)$ & $66(54.5)$ \\
\hline Sweden & 119 (3.3) & 51.600 & 2.3 & $50(42.0)$ & $69(58.0)$ \\
\hline Japan & $117(3.2)$ & 38.895 & 3.0 & $91(77.8)$ & $26(22.2)$ \\
\hline
\end{tabular}

Inter - country collaboration $=$ international collaboration 


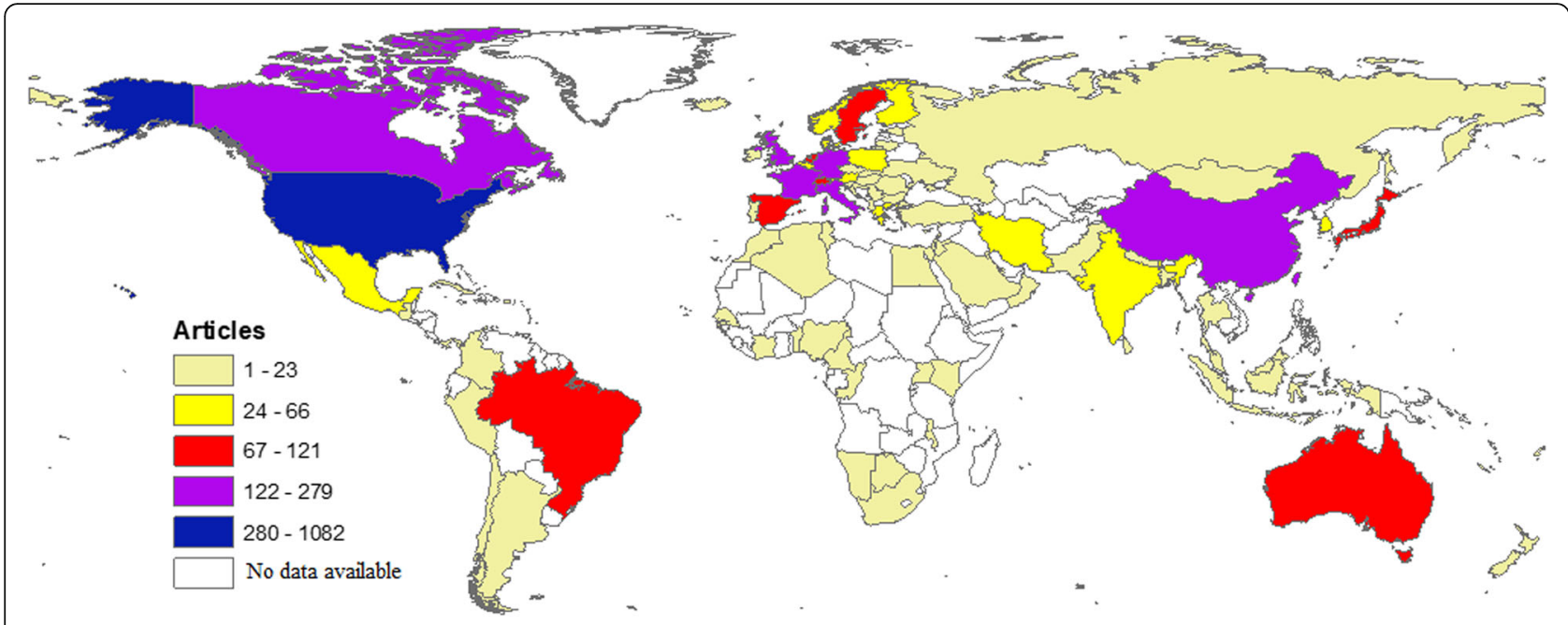

Fig. 4 Geographical distribution of published research in outdoor air pollution and respiratory health (1900 - 2017)

The presence of active institutions and many high impact journals in the field of environmental health and respiratory medicine issued from the USA contributed to the leadership of USA in this field. Research output in any field is a function of money allocated to research as well as public health agendas of the country. The leadership of the USA was seen in several other scientific subjects [55-58]. The fact that English was the primary language of literature published in journals indexed in Scopus might have created some sort of bias toward English-speaking countries.

\section{International collaboration}

Outdoor air pollution is a global health concern and international collaboration in this field is necessary. In our study, the extent of international collaboration in research was relatively high, particularly within European countries and between USA and Asian countries. The WHO Collaborating Centre for Air Quality Management and Air Pollution Control (WHO CC) is working with member states in Europe and Asia to encourage collaboration in air quality programs through interaction and networking [59].

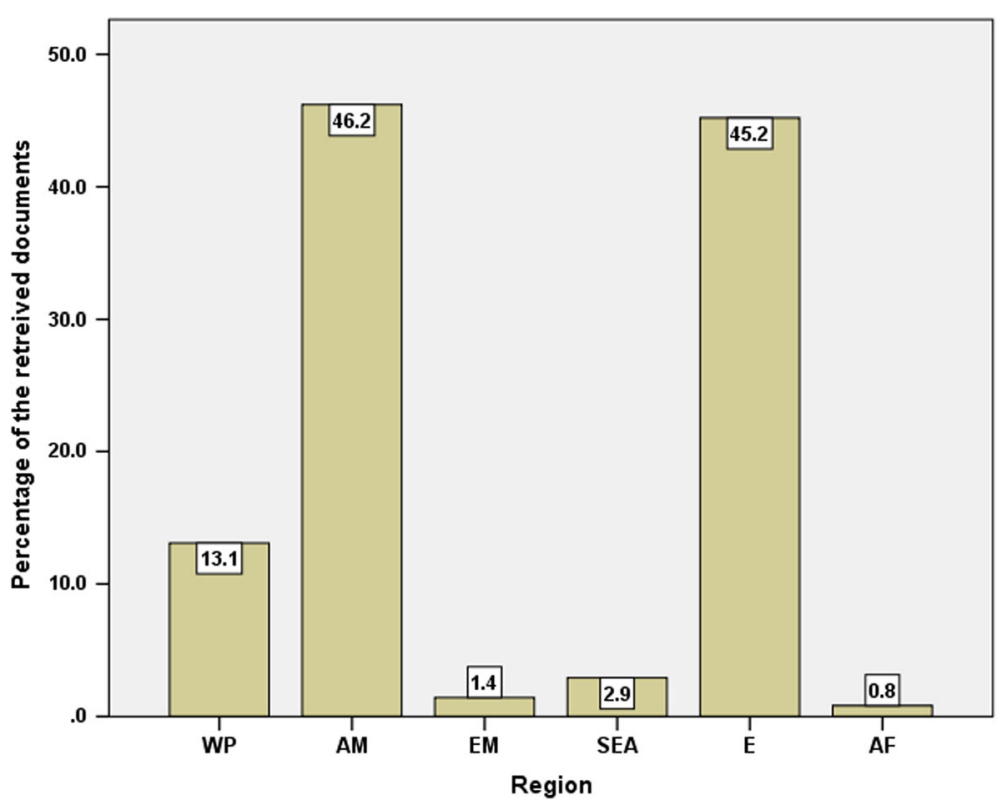

Fig. 5 Geographical distribution of published research in outdoor air pollution and respiratory health (1900 - 2017) based on WHO world region. WP: Western Pacific; EM: Eastern Mediterranean; E: Europe; SEA: South Eastern Asia; AM: Americas; AF: Africa 


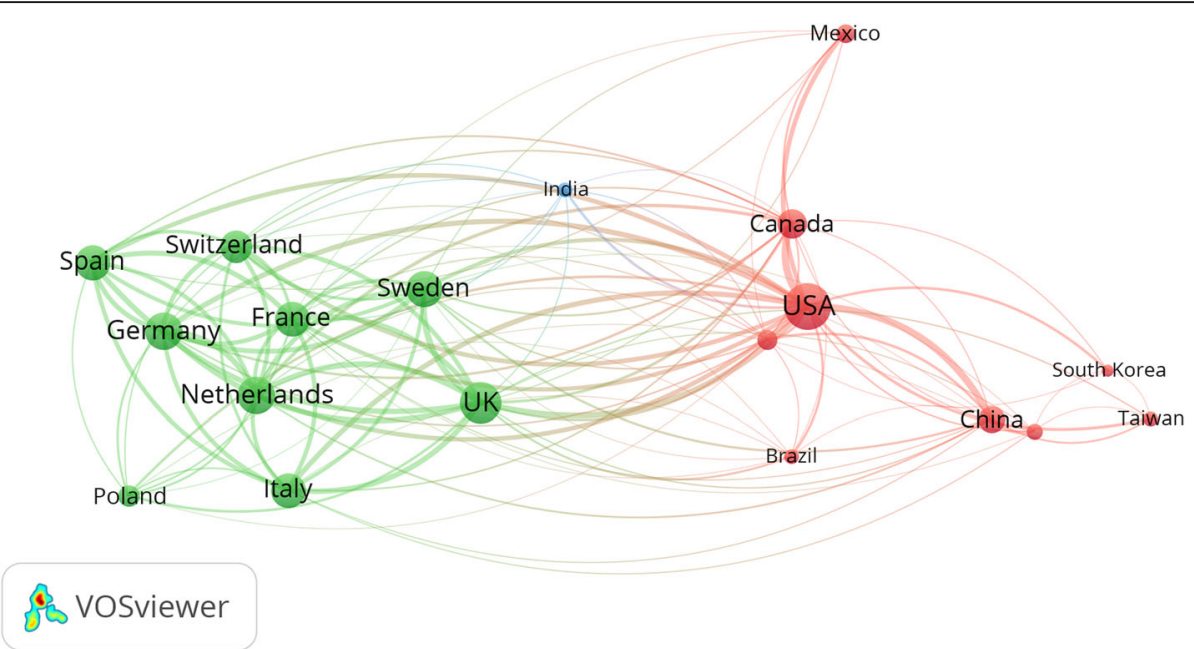

Fig. 6 Network visualization map of research collaboration in outdoor air pollution and respiratory health (1900 - 2017)

\section{Highly cited documents}

The top cited documents in the field was about the relationship between outdoor air pollution and lung cancer; and received a large number of citations suggestive of great importance. The International Agency for Research on Cancer [60], which is part of the WHO, has classified outdoor air pollution, as a whole, as a cancer-causing agent (carcinogen) [60]. The International Agency for Research on Cancer (IARC) concluded that outdoor air pollution causes lung cancer and is associated with increased risk for bladder cancer. Urgent action to minimize level of outdoor air pollution and exposure of population to such carcinogenic pollutants is necessary, particularly in cities with high levels of outdoor air pollution [61, 62].

\section{Strength and limitations}

It is the first to assess research activity in the field of outdoor air pollution - related respiratory health. Our study documented the accelerated increase in publications and the role of international collaboration. However, our study has a number of limitations. The Scopus database is a comprehensive and large database that includes different disciplines, but some peer - reviewed journals are not indexed in Scopus. This is particularly true for journals published from India, China, Indonesia, and other Asian and African countries where outdoor air pollution is a real public health problem. Therefore, documents published in un-indexed journals were not retrieved. Secondly, the results presented in this study reflect the search strategy implemented which is comprehensive in the subject but the presence of false positive and false negative results cannot be ruled out. This is true in all bibliometric studies [6367]. Thirdly, when listing active authors and institutions, the authors depended on the outcome obtained from the Scopus. However, some authors might have more than one Scopus profile or might have their name written in

Table 4 Top active institutions/organizations in publishing documents in air pollution - related respiratory health (1900 - 2017)

\begin{tabular}{llll}
\hline Institution/Organization (country affiliation) & Frequency & $\%$ & $N=3635$ \\
\hline Harvard School of Public Health & & 2.5 \\
United States Environmental Protection Agency & 92 & 2.4 & 34 \\
University of Southern California & 89 & 1.8 & 36 \\
The University of North Carolina at Chapel Hill & 65 & 1.8 & 26 \\
University of Washington, Seattle & 64 & 1.7 & 1.7 \\
Inserm & 61 & 1.6 & 28 \\
The University of British Columbia & 60 & 1.5 & 32 \\
Utrecht University & 58 & 1.4 & 29 \\
Helmholtz Center Munich German Research & 53 & 1.4 & 29 \\
Center for Environmental Health & 52 & & 23 \\
Universitat Basel & 52 & & 29 \\
\hline
\end{tabular}


Table 5 Top 10 cited documents in air pollution - related respiratory health $(1900-2017)$

\begin{tabular}{|c|c|c|}
\hline Reference & Title & Cited by \\
\hline [80] & $\begin{array}{l}\text { "Lung cancer, cardiopulmonary mortality, and } \\
\text { long-term exposure to fine particulate air } \\
\text { pollution" }\end{array}$ & 4294 \\
\hline [81] & $\begin{array}{l}\text { "Acute respiratory effects of particulate air } \\
\text { pollution" }\end{array}$ & 1561 \\
\hline [82] & $\begin{array}{l}\text { "Fine particulate air pollution and hospital } \\
\text { admission for cardiovascular and respiratory } \\
\text { diseases" }\end{array}$ & 1088 \\
\hline [83] & $\begin{array}{l}\text { "Respiratory effects are associated with the } \\
\text { number of ultrafine particles" }\end{array}$ & 975 \\
\hline [84] & "Pulmonary effects of inhaled ultrafine particles" & 855 \\
\hline [85] & $\begin{array}{l}\text { "The effect of air pollution on lung development } \\
\text { from } 10 \text { to } 18 \text { years of age" }\end{array}$ & 729 \\
\hline [86] & $\begin{array}{l}\text { "Particulate air pollution and hospital emergency } \\
\text { room visits for asthma in Seattle" }\end{array}$ & 510 \\
\hline [87] & $\begin{array}{l}\text { "Air pollution from truck traffic and lung function } \\
\text { in children living near motorways" }\end{array}$ & 467 \\
\hline [88] & $\begin{array}{l}\text { "Acute effects of particulate air pollution on } \\
\text { respiratory admissions: Results from APHEA } 2 \\
\text { project" }\end{array}$ & 465 \\
\hline [89] & $\begin{array}{l}\text { "Asthma in exercising children exposed to ozone: } \\
\text { A cohort study" }\end{array}$ & 464 \\
\hline
\end{tabular}

different articles in different ways which will affect their research output and therefore their rank as well. Same applies to active institutions where the name of the institution might be written in different articles in different ways which will affect their research output and rank as well. Furthermore, the authors used the keyword "environment" in the search strategy in a strict way to avoid false positive results since not all environmental pollution could fit the scope of the current study which focused on outdoor air pollution and its impact on respiratory health. In this regard, the authors also avoided the use of the keyword "climate" in the search strategy to keep the research question focused on outdoor air pollution, particularly those produced by industry. Finally, it should be emphasized that the list of highly cited articles does not mean that these articles are the only influential ones in the field. The citation process is dynamic and sometimes high citation reflects self-citation rather than impact. There were many influential and highly cited articles in the field that were not listed in the highly cited article [68-79].

\section{Conclusions}

Growth of publications in outdoor air pollution - related respirator health is rapidly increasing. However, limited research output and international collaboration were seen in world regions such as the Middle East, Africa, and South-East Asia. International multidisciplinary research network, involving countries with high levels of air pollution and limited resources, are needed. Research in atmospheric pollution should also be directed toward prevention of air pollution problems by investing more in green technology.

The results presented in this study are indicative of how research activity is interacting with the urgent acceleration of the air pollution crisis at the global level. Furthermore, the research activity is indicative of the response rate adopted by certain countries to face this global problem in a responsible way. Pressure groups can use the research activity to enforce certain environmental and industrial agendas on politicians and political campaigns. Countries with high levels of outdoor air pollution, and therefore, poor air quality, need to get engaged in research pertaining to this field to provide health policymakers with baseline data for future action. Establishing research center for monitoring national air quality and level of air pollution is a step forward that needs to be adopted by all countries. Such centers could include scientists from different disciplines who can collaborate to convert research findings into national agendas and policies. At the national levels, different world countries need to adopt strict guidelines for air quality. Collaboration between industry and health authorities is needed to implement measures that could significantly reduce the levels of particulate matter. The outdoor air pollution is a global public health and therefore research networking between developed countries and developing countries with high levels of air pollution should be prioritized. The Chinese model in controlling air pollution and minimizing its health consequences could be of a global benefit. Finally, since the respiratory effects of air pollution are affecting children, there is a need to educate and increase the awareness of parents regarding this issue.

\section{Additional file}

Additional file 1: Research strategy with keywords. (DOCX $17 \mathrm{~kb}$ )

\section{Abbreviations}

IARC: International Agency for Research on Cancer; IRB: Institutional Review Board; WHO: World Health Organization

\section{Acknowledgments}

The authors would like to thank An-Najah National University for giving the opportunities to this study.

\section{Availability of data and materials}

Data are available in additional file.

\section{Authors' contributions}

AS conceptualized and designed the study, coordinated the study and data analysis, interpreted the data, and did the final write-up of the manuscript. WS, SZ, SA; designed the method, data extraction, data analysis, data interpretation, and writing the manuscript. All authors read and approved the final manuscript. 


\section{Ethics approval and consent to participate}

Not applicable

\section{Competing interests}

The authors declare that they have no competing interests.

\section{Publisher's Note}

Springer Nature remains neutral with regard to jurisdictional claims in published maps and institutional affiliations.

\section{Author details}

'Division of Biomedical Sciences, Department of Physiology, Pharmacology and Toxicology, College of Medicine and Health Sciences, An-Najah National University, Nablus, Palestine. ${ }^{2}$ Department of Clinical and Community Pharmacy, College of Medicine and Health Sciences, An-Najah National University, Nablus, Palestine.

\section{Received: 16 January 2018 Accepted: 18 April 2018 Published online: 01 June 2018}

\section{References}

1. Seinfeld $\mathrm{JH}$, Pandis S. Atmospheric chemistry and physics: from air pollution to climate change. Volume 2nd ed. New York: John Wiley; 2006.

2. Nemmar A, Holme JA, Rosas I, Schwarze PE, Alfaro-Moreno E. Recent advances in particulate matter and nanoparticle toxicology: a review of the in vivo and in vitro studies. Biomed Res Int. 2013;2013:279371.

3. Venkatesan P. WHO report: air pollution is a major threat to health. Lancet Respir Med. 2016:4(5):351.

4. Landrigan PJ. Air pollution and health. Lancet Public Health. 2017;2(1):e4-5.

5. World Health Organization (WHO). WHO releases country estimates on air pollution exposure and health impact. [cited 2018 March 12]; Available from: http://www.who.int/mediacentre/news/releases/2016/air-pollution-estimates/en/

6. Khreis H, Kelly C, Tate J, Parslow R, Lucas K, Nieuwenhuijsen M. Exposure to traffic-related air pollution and risk of development of childhood asthma: a systematic review and meta-analysis. Environ Int. 2017:100:1-31.

7. Bloemsma LD, Hoek G, Smit LA. Panel studies of air pollution in patients with COPD: systematic review and meta-analysis. Environ Res. 2016;151:458-68.

8. Checa Vizcaino MA, Gonzalez-Comadran M, Jacquemin B. Outdoor air pollution and human infertility: a systematic review. Fertil Steril. 2016;106(4): 897-904. e891

9. Zanoli L, Lentini P, Granata A, Gaudio A, Fatuzzo P, Serafino L, et al. A systematic review of arterial stiffness, wave reflection and air pollution. Mol Med Rep. 2017;15(5):3425-9.

10. Power MC, Adar SD, Yanosky JD, Weuve J. Exposure to air pollution as a potential contributor to cognitive function, cognitive decline, brain imaging, and dementia: a systematic review of epidemiologic research. Neurotoxicology. 2016;56:235-53.

11. Siddika N, Balogun HA, Amegah AK, Jaakkola JJ. Prenatal ambient air pollution exposure and the risk of stillbirth: systematic review and metaanalysis of the empirical evidence. Occup Environ Med. 2016;73(9):573-81.

12. Orellano P, Quaranta N, Reynoso J, Balbi B, Vasquez J. Effect of outdoor air pollution on asthma exacerbations in children and adults: systematic review and multilevel meta-analysis. PLoS One. 2017:12(3):e0174050.

13. Jacobs M, Zhang G, Chen S, Mullins B, Bell M, Jin L, et al. The association between ambient air pollution and selected adverse pregnancy outcomes in China: a systematic review. Sci Total Environ. 2017;579:1179-92.

14. Air and Waste Management Association. Asia renews commitment to fight air pollution at the 2014 better air quality conference. EM: Air and Waste Management Association's Magazine for Environmental Managers [Conference Paper] 2015 [cited 2018 February 12]; Available from: http:// cleanairasia.org/wp-content/uploads/portal/files/documents/17_asia_ renews_commitment_to_fight_air_pollution_-_february_2015.pdf.

15. Vichit-Vadakan N, Vajanapoom N, Ostro B. The Public Health and Air Pollution in Asia (PAPA) project: estimating the mortality effects of particulate matter in Bangkok, Thailand. Environ Health Perspect. 2008; 116(9):1179-82

16. Wong CM, Vichit-Vadakan N, Kan H, Qian Z. Public Health and Air Pollution in Asia (PAPA): a multicity study of short-term effects of air pollution on mortality. Environ Health Perspect. 2008;116(9):1195-202.
17. Lelieveld J, Crutzen PJ, Ramanathan V, Andreae MO, Brenninkmeijer CM, Campos T, et al. The Indian Ocean experiment: widespread air pollution from South and Southeast Asia. Science. 2001;291(5506):1031-6.

18. Brimblecombe $\mathrm{P}$, Grossi CM. The bibliometrics of atmospheric environment Atmos Environ. 2009;43(1):9-12.

19. Wang F, Jia X, Wang $X$, Zhao $Y$, Hao W. Particulate matter and atherosclerosis: a bibliometric analysis of original research articles published in 1973-2014. BMC Public Health. 2016;16(1):348

20. Kolle SR, Thyavanahalli SH. Global research on air pollution between 2005 and 2014: a bibliometric study. Collect Build. 2016;35(3):84-92.

21. Nykiforuk $\mathrm{Cl}$, Osler GE, Viehbeck $\mathrm{S}$. The evolution of smoke-free spaces policy literature: a bibliometric analysis. Health Policy. 2010;97(1):1-7.

22. Andrade A, Dominski FH, Coimbra DR. Scientific production on indoor air quality of environments used for physical exercise and sports practice: bibliometric analysis. J Environ Manag. 2017:196:188-200.

23. Zell H, Quarcoo D, Scutaru C, Vitzthum K, Uibel S, Schoffel N, et al. Air pollution research: visualization of research activity using density-equalizing mapping and scientometric benchmarking procedures. J Occup Med Toxicol. 2010;5(1):5.

24. Jia X, Guo X. Bibliometric analysis of associations between ambient pollution and reproductive and developmental health. Zhonghua Yu Fang Yi Xue Za Zhi. 2014;48(6):521-6.

25. Falagas ME, Pitsouni El, Malietzis GA, Pappas G. Comparison of PubMed, Scopus, Web of Science, and Google Scholar: strengths and weaknesses. FASEB J. 2008;22(2):338-42.

26. Bakkalbasi N, Bauer K, Glover J, Wang L. Three options for citation tracking: Google Scholar, Scopus and Web of Science. Biomed Digit Libr. 2006:3:7.

27. Kulkarni AV, Aziz B, Shams I, Busse JW. Comparisons of citations in Web of Science, Scopus, and Google Scholar for articles published in general medical journals. JAMA. 2009:302(10):1092-6.

28. De Groote SL, Raszewski R. Coverage of Google Scholar, Scopus, and Web of Science: a case study of the h-index in nursing. Nurs Outlook. 2012;60(6):391-400.

29. Abdo N, Khader YS, Abdelrahman M, Graboski-Bauer A, Malkawi M, Al-Sharif $M$, et al. Respiratory health outcomes and air pollution in the Eastern Mediterranean region: a systematic review. Rev Environ Health. 2016;31(2): 259-80.

30. Zhao L, Liang HR, Chen FY, Chen Z, Guan WJ, Li JH. Association between air pollution and cardiovascular mortality in China: a systematic review and meta-analysis. Oncotarget. 2017:8(39):66438-48.

31. Gearing RE, Mian IA, Barber J, Ickowicz A. A methodology for conducting retrospective chart review research in child and adolescent psychiatry. J Can Acad Child Adolesc Psychiatry. 2006;15(3):126-34.

32. Kimberlin CL, Winterstein AG. Validity and reliability of measurement instruments used in research. Am J Health Syst Pharm. 2008;65(23): 2276-84.

33. Banks NJ. Designing medical record abstraction forms. Int J Qual Health Care. 1998:10(2):163-7.

34. Allison JJ, Wall TC, Spettell CM, Calhoun J, Fargason CA Jr, Kobylinski RW, et al. The art and science of chart review. Jt Comm J Qual Improv. 2000;26(3): 115-36

35. Hallgren K. Computing inter-rater reliability for observational data: an overview and tutorial. Tutor Quant Methods Psychol. 2003;8(1):23-34.

36. Ellegaard $\mathrm{O}$, Wallin JA. The bibliometric analysis of scholarly production: how great is the impact? Scientometrics. 2015;105(3):1809-31.

37. van Eck NJ, Waltman L. Software survey: VOSviewer, a computer program for bibliometric mapping. Scientometrics. 2010;84(2):523-38.

38. Van Eck NJ, Waltman L. Text mining and visualization using VOSviewer. arXiv preprint arXiv:11092058 2011 [cited 2018 March 12]; Available from: https://arxiv.org/abs/1109.2058.

39. van Eck NJ, Waltman L. VOSviewer manual. Leiden: Univeristeit Leiden; 2013. [cited 2018 March 12]; Available from: http://www.vosviewer.com/ documentation/Manual_VOSviewer_1.5.4.pdf

40. Mills CA. Urban air pollution and respiratory diseases. Am J Epidemiol. 1943; 37(2):131-41.

41. World Health Organization (WHO). Mortality and burden of disease from ambient air pollution. Global Health Observatory (GHO) data 2012 [cited 2018 March 15]; Available from: http://www.who.int/gho/phe/outdoor_air_ pollution/burden_text/en/.

42. Lelieveld J, Evans JS, Fnais M, Giannadaki D, Pozzer A. The contribution of outdoor air pollution sources to premature mortality on a global scale. Nature. 2015;525(7569):367-71. 
43. Song Q, Christiani DC, XiaorongWang RJ. The global contribution of outdoor air pollution to the incidence, prevalence, mortality and hospital admission for chronic obstructive pulmonary disease: a systematic review and meta-analysis. Int J Environ Res Public Health. 2014;11(11):11822-32.

44. Lu F, Zhou L, Xu Y, Zheng T, Guo Y, Wellenius GA, et al. Short-term effects of air pollution on daily mortality and years of life lost in Nanjing, China. Sci Total Environ. 2015;536:123-9.

45. Ji H, Biagini Myers JM, Brandt EB, Brokamp C, Ryan PH, Khurana Hershey GK. Air pollution, epigenetics, and asthma. Allergy Asthma Clin Immunol. 2016:12(1):51.

46. Chen R, Hu B, Liu Y, Xu J, Yang G, Xu D, et al. Beyond PM2.5: the role of ultrafine particles on adverse health effects of air pollution. Biochim Biophys Acta. 2016;1860(12):2844-55.

47. Danusevičius D, Marozas V, Augustaitis A, Plaušyte E. A fast screening approach for genetic tolerance to air pollution in Scots pine field tests. IFOREST. 2013;6(4):262-7.

48. McCullough SD, Dhingra R, Fortin MC, Diaz-Sanchez D. Air pollution and the epigenome: a model relationship for the exploration of toxicoepigenetics. Curr Opin Toxicol. 2017;6:18-25.

49. Silveyra P, Floros J. Air pollution and epigenetics: effects on SP-A and innate host defence in the lung. Swiss Med Wkly. 2012;142(MAY):w13579.

50. Sweileh WM, Shraim NY, Al-Jabi SW, Sawalha AF, AbuTaha AS, Zyoud SH. Bibliometric analysis of global scientific research on carbapenem resistance (1986-2015). Ann Clin Microbiol Antimicrob. 2016;15(1):56

51. Sweileh WM, AbuTaha AS, Sawalha AF, Al-Khalil S, Al-Jabi SW, Zyoud SH. Bibliometric analysis of worldwide publications on multi-, extensively, and totally drug - resistant tuberculosis (2006-2015). Multidiscip Respir Med. 2016;11:45.

52. Yang $G$, Wang $Y$, Zeng $Y$, Gao GF, Liang $X$, Zhou $M$, et al. Rapid health transition in China, 1990-2010: findings from the Global Burden of Disease Study 2010. Lancet. 2013;381(9882):1987-2015.

53. World Health Organization (WHO). China tops WHO list for deadly outdoor air pollution. 2016 [cited 2017 October 21]; Available from: https://www. theguardian.com/environment/2016/sep/27/more-than-million-died-due-airpollution-china-one-year.

54. Government of China. Ambient air quality standards (in Chinese). GB 30952012. 2012 [cited 2018 March 13]; Available from: http://kjs.mep.gov.cn/ hibhbz/bzwb/dqhjbh/dahjzlbz/201203/W020120410330232398521.pdf.

55. Sweileh WM. Bibliometric analysis of peer-reviewed literature in transgender health (1900 - 2017). BMC Int Health Hum Rights. 2018;18(1):16.

56. Sweileh WM, Al-Jabi SW, Sawalha AF, AbuTaha AS, Zyoud SH. Bibliometric analysis of publications on Campylobacter: (2000-2015). J Health Popul Nutr. 2016:35(1):39.

57. Sweileh WM, Al-Jabi SW, Sawalha AF, Zyoud SH. Bibliometric profile of the global scientific research on autism spectrum disorders. Spring. 2016;5(1):1480.

58. Zyoud SH, Waring WS, Al-Jabi SW, Sweileh WM, Awang R. The 100 most influential publications in paracetamol poisoning treatment: a bibliometric analysis of human studies. Spring. 2016;5(1):1534.

59. World Health Organization (WHO). WHO collaborating centre for air quality management. 2015 [cited 2018 March 15]; Available from: http://www. umweltbundesamt.de/en/topics/health/commissions-working-groups/whocollaborating-centre-for-air-quality-management.

60. International Agency for Research on Cancer (IARC). World Health Organization: outdoor air pollution causes cancer. 2013 [cited 2018 March 13]; Available from: https://www.cancer.org/latest-news/world-healthorganization-outdoor-air-pollution-causes-cancer.html.

61. Loomis D, Huang W, Chen G. The International Agency for Research on Cancer (IARC) evaluation of the carcinogenicity of outdoor air pollution: focus on China. Chin J Cancer. 2014;33(4):189-96.

62. Guillerm N, Cesari G. Fighting ambient air pollution and its impact on health: from human rights to the right to a clean environment. Int J Tuberc Lung Dis. 2015;19(8):887-97.

63. Sweileh WM. Bibliometric analysis of medicine - related publications on refugees, asylum-seekers, and internally displaced people: 2000 - 2015. BMC Int Health Hum Rights. 2017;17(1):7.

64. Sweileh WM. Global research trends of World Health Organization's top eight emerging pathogens. Glob Health. 2017;13(1):9.

65. Sweileh WM, Al-Jabi SW, AS AT, Zyoud SH, FMA A, Sawalha AF. Bibliometric analysis of worldwide scientific literature in mobile - health: 2006-2016. BMC Med Inform Decis Mak. 2017;17(1):72.
66. Zyoud SH, Sweileh WM, Awang R, Al-Jabi SW. Global trends in research related to social media in psychology: mapping and bibliometric analysis. Int J Ment Health Syst. 2018;12(1):4.

67. Zyoud SH, Waring WS, Al-Jabi SW, Sweileh WM. Global cocaine intoxication research trends during 1975-2015: a bibliometric analysis of Web of Science publications. Subst Abuse Treat Prev Policy. 2017;12(1):6.

68. Hoek G, Krishnan RM, Beelen R, Peters A, Ostro B, Brunekreef B, et al. Longterm air pollution exposure and cardio- respiratory mortality: a review. Environ Health. 2013;12(1):43.

69. Samoli E, Nastos PT, Paliatsos AG, Katsouyanni K, Priftis KN. Acute effects of air pollution on pediatric asthma exacerbation: evidence of association and effect modification. Environ Res. 2011;111(3):418-24.

70. D'Amato G, Cecchi L, D'Amato M, Liccardi G. Urban air pollution and climate change as environmental risk factors of respiratory allergy: an update. J Investig Allergol Clin Immunol. 2010;20(2):95-102.

71. Li N, Xia T, Nel AE. The role of oxidative stress in ambient particulate matterinduced lung diseases and its implications in the toxicity of engineered nanoparticles. Free Radic Biol Med. 2008;44(9):1689-99.

72. Gauderman WJ, Avol E, Lurmann F, Kuenzli N, Gilliland F, Peters J, et al. Childhood asthma and exposure to traffic and nitrogen dioxide. Epidemiology. 2005;16(6):737-43.

73. D'Amato G, Liccardi G, D'Amato M, Holgate S. Environmental risk factors and allergic bronchial asthma. Clin Exp Allergy. 2005;35(9):1113-24.

74. MacNee W, Donaldson K. Mechanism of lung injury caused by PM10 and ultrafine particles with special reference to COPD. Eur Respir J Suppl. 2003; 21(40):475-51S.

75. Li N, Hao M, Phalen RF, Hinds WC, Nel AE. Particulate air pollutants and asthma. A paradigm for the role of oxidative stress in PM-induced adverse health effects. Clin Immunol. 2003;109(3):250-65.

76. D'Amato G, Liccardi G, D'Amato M, Cazzola M. The role of outdoor air pollution and climatic changes on the rising trends in respiratory allergy. Respir Med. 2001;95(7):606-11.

77. Donaldson K, Stone V, Gilmour PS, Brown DM, MacNee W. Ultrafine particles: mechanisms of lung injury. Philos Trans Royal Soc A Math Phys Eng Sci. 2000;358(1775):2741-9.

78. Ackermann-Liebrich U, Leuenberger P, Schwartz J, Schindler C, Monn C, Bolognini $\mathrm{G}$, et al. Lung function and long term exposure to air pollutants in Switzerland. Study on Air Pollution and Lung Diseases in Adults (SAPALDIA) team. Am J Respir Crit Care Med. 1997;155(1):122-9.

79. Schwartz J. Short term fluctuations in air pollution and hospital admissions of the elderly for respiratory disease. Thorax. 1995;50(5):531-8.

80. Pope lii CA, Burnett RT, Thun MJ, Calle EE, Krewski D, Ito K, et al. Lung cancer, cardiopulmonary mortality, and long-term exposure to fine particulate air pollution. JAMA. 2002;287(9):1132-41.

81. Dockery DW, Pope CA 3rd. Acute respiratory effects of particulate air pollution. Annu Rev Public Health. 1994:15:107-32.

82. Dominici F, Peng RD, Bell ML, Pham L, McDermott A, Zeger SL, et al. Fine particulate air pollution and hospital admission for cardiovascular and respiratory diseases. JAMA. 2006;295(10):1127-34.

83. Peters A, Wichmann HE, Tuch T, Heinrich J, Heyder J. Respiratory effects are associated with the number of ultrafine particles. Am J Respir Crit Care Med. 1997;155(4):1376-83

84. Oberdörster G. Pulmonary effects of inhaled ultrafine particles. Int Arch Occup Environ Health. 2001;74(1):1-8.

85. Gauderman WJ, Avol E, Gilliland F, Vora H, Thomas D, Berhane K, et al. The effect of air pollution on lung development from 10 to 18 years of age. $\mathrm{N}$ Engl J Med. 2004;351(11):1057-67.

86. Schwartz J, Slater D, Larson TV, Pierson WE, Koenig JQ. Particulate air pollution and hospital emergency room visits for asthma in Seattle. Am Rev Respir Dis. 1993;147(4):826-31.

87. Brunekreef $B$, Janssen NA, de Hartog J, Harssema H, Knape M, van Vliet $P$. Air pollution from truck traffic and lung function in children living near motorways. Epidemiology. 1997;8(3):298-303.

88. Atkinson RW, Anderson HR, Sunyer J, Ayres J, Baccini M, Vonk JM, et al. Acute effects of particulate air pollution on respiratory admissions: results from APHEA 2 project. Air pollution and health: a European approach. Am J Respir Crit Care Med. 2001;164(10 Pt 1):1860-6.

89. McConnell R, Berhane K, Gilliland F, London SJ, Islam T, Gauderman WJ, et al. Asthma in exercising children exposed to ozone: a cohort study. Lancet. 2002;359(9304):386-91. 